\title{
Modern fetal surgery-a historical review of the happenings that shaped modern fetal surgery and its practices
}

\author{
Lauren L. Evans, Michael R. Harrison \\ Department of Surgery, Division of Pediatric Surgery, University of California, San Francisco, CA, USA \\ Contributions: (I) Conception and design: All authors; (II) Administrative support: All authors; (III) Provision of study materials or patients: All \\ authors; (IV) Collection and assembly of data: All authors; (V) Data analysis and interpretation: All authors; (VI) Manuscript writing: All authors; (VII) \\ Final approval of manuscript: All authors. \\ Correspondence to: Michael R. Harrison, MD. 550 16th Street, 6th Floor UCSF \#0570, San Francisco, CA 94158, USA. Email: Michael.Harrison@ucsf.edu.
}

\begin{abstract}
The history of fetal surgery is one of constant evolution. Over the last 50 years, fetal surgery has progressed from a mere idea to an internationally respected innovative field of surgery. This article aims to provide a historical review of how the enterprise of maternal-fetal surgery came to be its modern version. This review is less focused on the history of specific therapies for a relatively small number of conditions, and more on how the whole field of maternal-fetal surgery evolved. The various internal and external influences that steered the field's evolution are discussed in chronologic order. Since the start of modern fetal surgery in the 1980s, large paradigm shifts have characterized the growth of the field as a whole. Innovative interventions are now based on physiologic manipulation as opposed to simple anatomic repair, fetoscopy has become the more frequently preferred surgical approach, and rigorous scientific evaluation with randomized controlled trials is now the standard expected by the community. In a very similar fashion to when the field first began in the early 1980s, recently community's leaders have risen to protect the integrity of maternalfetal surgery by publishing ethical guidelines for innovation and clinical practice. This incredible history of innovation, rigorous science and ethical contemplation is the foundation on which modern maternal-fetal surgery rests.
\end{abstract}

Keywords: Fetal surgery; fetal therapy; innovative therapies; fetoscopy; fetal ultrasonography

Submitted Mar 28, 2020. Accepted for publication Nov 05, 2020.

doi: $10.21037 /$ tp-20-114

View this article at: http://dx.doi.org/10.21037/tp-20-114

\section{Introduction}

Since it was founded, the field of modern fetal surgery has been in constant evolution. This article is a historical review of how the field of maternal-fetal surgery has evolved. We highlight the milestones and events, both good and bad, that made fetal surgery into the successful clinical enterprise it is today. The historical events included are not a comprehensive review of the innumerable noteworthy events in the history of fetal therapy, nor is this review unbiased, since one of the authors lived through it. A more comprehensive review of the field's major historical milestones is summarized in Table 1 .

The history of maternal-fetal surgery is essentially one of experimentation and innovation inherently loaded with socially charged ethical dilemmas (44). Addressing the field's unique, and provocative, ethical considerations, has made the enterprise of fetal therapy one of the most successful stories of innovation in history. However, the evolution of maternal-fetal surgery has not been without controversy or criticism (60). The application of new innovative therapies to pregnant women has forced the development of new guidelines for ethical innovation and human trials.

Fetal surgery emerged in 1961 when Sir William Liley completed the first percutaneous fetal transfusion (1). By 1964, Asensio and Adamsons reported direct access to fetal circulation via open hysterotomy $(2,61)$. Work in fetal transfusion around the world resulted in the 1966 
Table 1 Major milestones in the evolution of modern maternal-fetal surgery

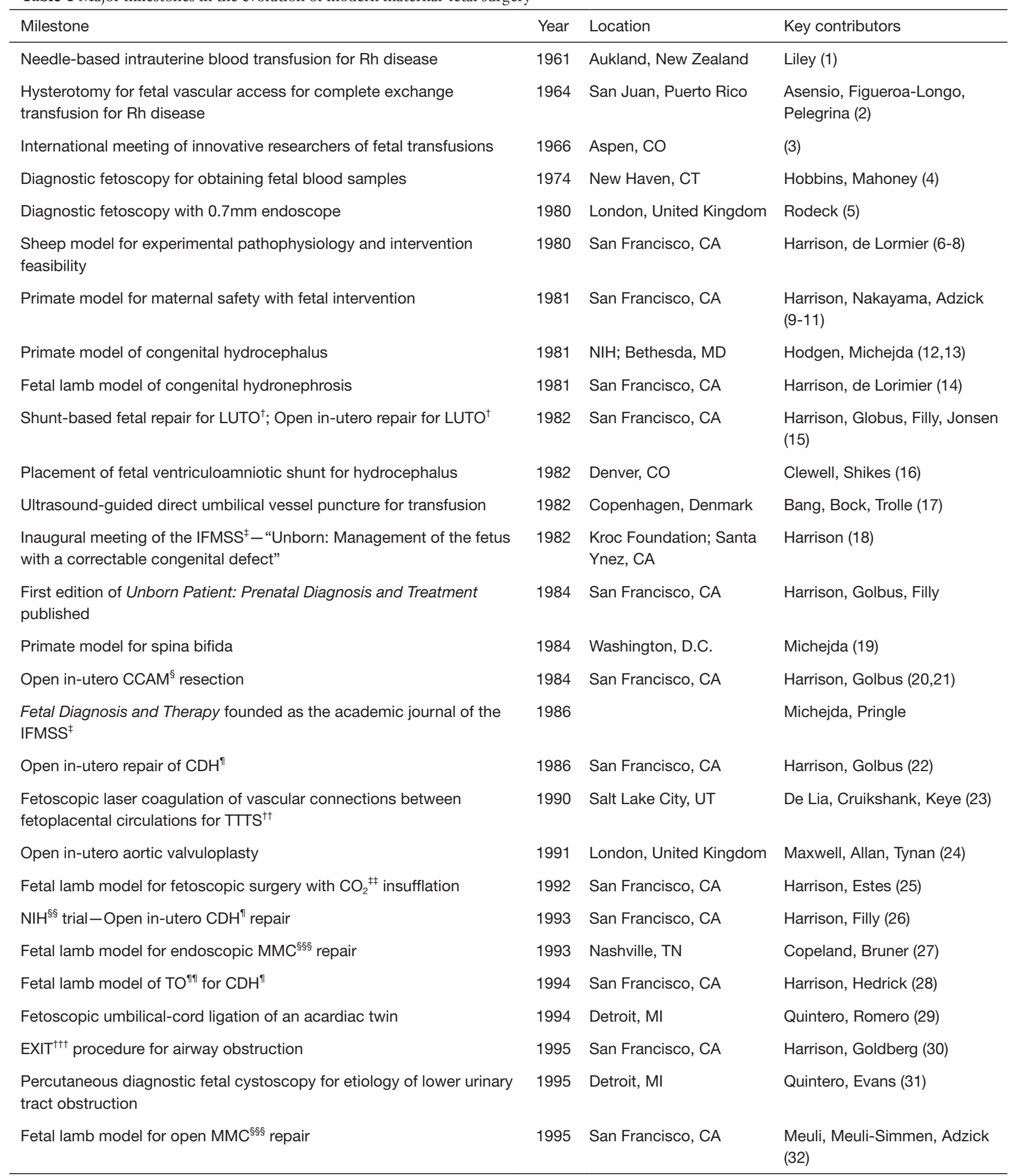

Table 1 (continued) 
Table 1 (continued)

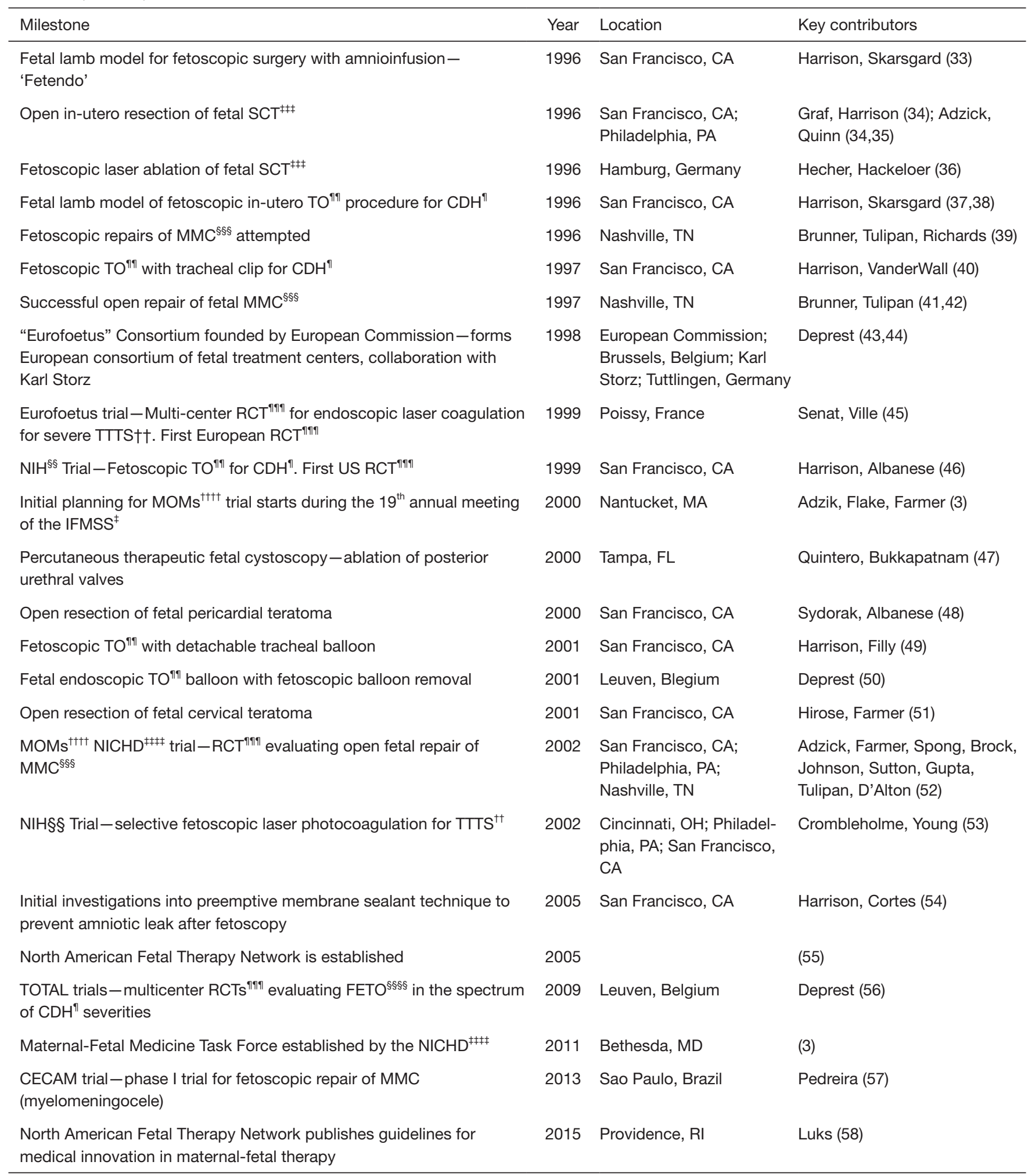

Table 1 (continued) 
Table 1 (continued)

\begin{tabular}{|c|c|c|c|}
\hline Milestone & Year & Location & Key contributors \\
\hline
\end{tabular}

international meeting of innovative researchers in fetal transfusions (3). Around the same time, the high morbidity and mortality with open interventions quickly came to light. Open hysterotomy was abandoned and it would be over a decade before open fetal surgery would be investigated again (3). Early innovators in fetal therapy were ahead of their time. Better supportive measures, including anesthesia and prenatal imaging, were needed before fetal surgery could truly emerge and reach its full potential.

\section{An idea becomes reality-the foundation of modern maternal-fetal surgery}

It's generally recognized that modern fetal surgery hatched in the mind of Michael Harrison $(3,44)$. In 1969, as an eager intern at Massachusetts General, Harrison assisted Dr. Hardy Hendren with a congenital diaphragmatic hernia $(\mathrm{CDH})$ repair. Despite Harrison's post-op vigil in the intensive care nursery, the infant passed away the following day $(62,63)$. The frustrating outcome sparked his first "crazy idea" of repairing a defect before birth. This first experience would shape Harrison's career, eventually draw him to the University of California San Francisco (UCSF), and ultimately make $\mathrm{CDH}$ central to the development of fetal therapy.

After residency, Harrison spent 6 months in Oslo, Norway investigating the natural history of CDH. Norway's national registry tracked all neonatal and prenatal deaths with autopsy reports, and provided a unique opportunity to determine the true incidence and mortality of $\mathrm{CDH}$ (63). Harrison uncovered that $50 \%$ of infants with $\mathrm{CDH}$ died before they could be accounted for officially. He dubbed the previously unappreciated deaths the "hidden mortality" (64). Harrison's discovery highlighted that the natural history of a disease discovered before birth was not necessarily the same if diagnosed after birth (63). Establishing the pathophysiology and evolution of fetal pathology before attempting intervention remains a cornerstone of innovation in fetal therapy.

Diagnostic fetoscopy and fetal ultrasound (US) were developed in parallel in the 1970s-1980s. In 1974, Hobbins and Mahoney reported the first successful diagnostic fetoscopy (4), however, further adoption of therapeutic fetoscopy was hindered by difficulty and invasiveness.

At King's College Hospital, Rodeck was a fierce champion of fetoscopic innovation for both diagnostic and therapeutic uses (5). Simultaneously, the development of fetal US gained enormous momentum. In 1977, Garrett and Kossoff reported the accurate prenatal diagnosis of CDH with US (3). By 1982, Bang reported the first USguided direct umbilical vessel puncture (17). Just as wide availability of reliable ultrasound made fetoscopy essentially obsolete, Rodeck successfully achieved direct access to fetal circulation under fetoscopic guidance (65). The improved accuracy and wide availability of US helped usher in the modern era of fetal surgery $(3,63)$.

As prenatal diagnostics reached new heights with landmark advancements in fetal US, Harrison arrived at UCSF. Al DeLorimier's work in fetal physiology and his fetal lamb model of CDH made Harrison confident UCSF was the best place to start the enterprise of maternalfetal surgery (63). Almost immediately, Harrison adopted the fetal-lamb model and began work establishing the pathophysiology of $\mathrm{CDH}$ and the physiologic effects of repair (6-8). Harrison and deLorimier's stepwise experimental approach in the fetal lamb model established both pathophysiology and feasibility of repair. Their paradigm had 4 central steps: surgically create a lesion, evaluate the resulting pathophysiology, perform the repair, and study the resulting physiologic effects (63). Harrison and deLormirier's experimental methodology for animal model work was rapidly adopted and remains the gold standard for initial investigations in fetal therapy today (66). Harrison went on to establish the pathophysiology and 
feasibility of repair in a large variety of neonatal pathologies, including fetal hydronephrosis due to lower urinary tract obstruction (LUTO) (14,67), hydrocephalus, and eventually myelomeningocele (MMC).

Harrison's team established a primate model for hysterotomy at the University of California Davis in 1981. For each intervention, the primate model established the corresponding maternal-fetal safety profile (9-11). The monkey colony also enabled investigators to examine longterm effects on the mother following intervention. The close evaluation of maternal future fertility and reproductive potential lead to the elimination of metal staples and the invention of absorbable staples for hysterotomy closure, a key step in ensuring safe maternal-fetal surgery (63). At the National Institutes of Health (NIH), Hodgen and Michejda established a primate model of hydrocephalus $(12,13)$. The early work establishing an animal model and experimental paradigm for repair of fetal pathologies set the stage for the successes the following year.

Fetal hydronephrosis due to LUTO and fetal hydrocephalus were the first disease processes to attract serious attention for fetal interventions (63). Both had established animal models and were highly amenable to ultrasound evaluation. In 1982, Harrison, and the early members of the UCSF Fetal Treatment Program (FTP), brought the concept of fetal therapy to life. In rapid succession, the first two fetal interventions were completed, both for congenital hydronephrosis. First, was the successful in-utero placement of a fetal vesicoamniotic shunt for LUTO (68). Shortly after, and unexpectedly, a desperate case presented with severe LUTO and complete oligohydramnios, not amenable to stent placement (63). In March, just weeks after their first triumph, the first ever open intervention for decompression of the fetal urinary system was a success $(15,63)$. By June, Clewell successfully placed a ventriculoamniotic shunt for fetal hydrocephalus (16). In just a few short months, the young enterprise of maternal-fetal surgery was off to a rapid start.

The UCSF FTP was essential to the early success of the enterprise. Frustrations with limited treatment options for many fetal pathologies brought together the disciplines involved in perinatal medicine. Collaboration between obstetrics, radiology, pediatric surgery, pediatrics and neonatology established the high-quality patient care required to deliver effective perinatal fetal care. The newly created UCSF FTP became the means of facilitating close collaboration between medical specialties that otherwise would not have worked together closely (63). This collaborative, multi-disciplinary delivery of patient care became the paradigm for human fetal surgery that guided the UCSF team and programs that later emerged (62).

\section{Promising but unproved}

A massive media frenzy erupted in response to reports of the first successful fetal interventions. The newly born enterprise had already caught the attention of the world. Harrison recognized early on that the enterprise was very fragile, and the relationship between fetal therapy and the world would need to be carefully nurtured. The delicate ethical issues of maternal-fetal surgery had the potential to create a hugely negative reaction from the public and the entire field of medicine (62). The early pioneers of fetal surgery knew that the future of the enterprise depended entirely on how the field would come to be viewed in the eyes of patients, medical colleagues and the general public (62).

The early international leaders of fetal therapy made a concerted effort to band-together and create a unified enterprise. In July of 1982, the UCSF team invited a multidisciplinary group of 24 experts, from 13 centers representing 5 countries, to gather at the Kroc Foundation property in Santa Ynez, CA. That first meeting, "Unborn: Management of the fetus with a correctable congenital defect", had Sir William Liley as an inspirational keynote speaker. In comfortable informality that encouraged openness, the group had frank, productive discussions on the future of the enterprise and strategies for moving forward (63). The group drafted a set of mutually agreed upon ethical guidelines for fetal interventions that were later published in a consensus statement (18). The guidelines first put forward by the group remain the foundation for the ethical practice of maternal-fetal surgery today (Table 2) (18). Spearheaded by Manning, the first two national registries for outcomes reporting were established for fetal hydrocephalus and fetal hydronephrosis. Just 4 years later, Manning published the registries early results showing shunts for congenital hydrocephalus produced discouraging outcomes. His report led to an international voluntary moratorium on shunts for hydrocephalus lasting almost 20 years $(63,68)$. Many of the participants of that initial meeting also contributed to the first textbook in the field: The Unborn Patient: Prenatal Diagnosis and Treatment by Michael Harrison, Mickey Golbus, and Roy Filly. Participants Michejda and Pringle collaborated on and later founded Fetal Diagnosis and Therapy in 1986, a journal that became the official academic voice of the International 
Table 2 Criteria for consideration of maternal-fetal surgery as outlined by the consensus statement from the International Fetal Medicine and Surgery Society after their inaugural meeting (18)

The disorder is the result of a structural defect that interferes with organ development and repair may result in normalization of fetal development

The natural history of the disorder has been defined in the untreated human fetus, including the spectrum of severity and associated prognoses

Prenatal diagnosis is accurate and can determine the severity of disease, evaluate for disease progression over time, and identify any additional congenital anomalies

There are no effective alternative postnatal treatment options otherwise available

The pathophysiology of the disorder and feasibility, efficacy and safety (fetal and maternal) of the proposed intervention have been validated experimentally in a pre-clinical animal model

Interventions are performed by a collaborative multidisciplinary provider team at a specialized fetal treatment center

Access to both high-risk obstetric and neonatal intensive care units as well as to bioethical and psychosocial consultation

All cases, regardless of outcome, are reported to a fetal treatment registry or are published in the medical literature, ideally both

Informed parental consent includes extensive family counseling, including potential risks and benefits of the intervention, all alternative treatment options, and familial agreement to continued long-term follow-up

Fetal Medicine and Surgery Society (IFMSS) (63). The group reconvened a year later and formally became the IFMSS (44). Potentially the most important standard established at the first meeting, and reinforced at every IFMSS meeting since, was participant's commitment to their responsibility for the stewardship of the field of fetal therapy as a whole (63).

Despite those early efforts, Harrison's apprehensions about the delicacy of the young enterprise would soon become a reality. Harrison describes the initial enterprise as "thriving, bawling, vibrant and rapidly growing... with the exploration of many new therapies" (63). Over the next decade, the early unfettered success of the field's inaugural years would give way to tribulations that almost lead to its premature (stillborn) demise. However, the lessons learned from early hurdles would help shape the future of the enterprise on an international scale (63).

By the early $1980 \mathrm{~s}$, the natural history and pathophysiology of CDH was established (69) and the feasibility of fetal repair had shown promising results in a fetal lamb model $(6-8,70,71)$. In 1984, Harrison's group performed the first open fetal repair of severe CDH (63). Between 1983 and 1989, the group completed a total of 6 open fetal repairs for the most severe cases of CDH. The experience was frustrating as well as disheartening. Despite the promising results with the initial lamb work, the human mortality rate was $77 \%$ (63). Most discouraging, 5 of 6 infants were found to have liver herniation, which made them unrepairable $(72,73)$. For the first time, the experimental results established in an animal model were not indicative of the clinical outcomes (72).

The first experience confirmed that outcome heavily depends on the presence of liver herniation and informed the decision to exclude patient's with liver herniation in future studies. In 1986 the first successful open fetal repair for CDH was completed and by 1990 the group reported 2 successful repairs (22). With a few wins under their belt, Harrison's group embarked on planning a proper NIHfunded phase I trial evaluating open fetal repair for $\mathrm{CDH}$ (26). Submitting a novel fetal therapy to a rigorous trial was bold and dangerous but the trial was a coming of age moment. It put modern fetal therapy on the map, while simultaneously almost causing the total ruin of the whole enterprise (63). An unprecedented amount of work was required to get the trial through the approval processes at the NIH and UCSF Committee on Human Research (CHR) (63). But in 1994, after a grueling 2-years of effort, the trial opened (26). Unfortunately, the real challenges had yet to start.

As the trial got started, initial data from a primate model yielded results supporting the use of nitroglycerin for prevention of preterm labor after hysterotomy (63). Optimistic about its potential clinical impact, maternal nitroglycerin was administered intra-operatively in patients enrolled in the trial. While nitroglycerin resulted in excellent tocolysis, it also caused several patients to develop severe pulmonary edema, resulting in a disaster that endangered 
the enterprise and temporarily shut down the FTP. Fortunately, the team's crash investigation revealed that the soluble propylene glycol was the culprit $(74,75)$. However, for the first time, a fetal intervention had resulted in serious, and thankfully reversible, maternal sequalae. Nitroglycerin use was rapidly abandoned but damage had been done, and with serious ramifications, the effects of which would be felt for years.

Trial protocols were immediately suspended and both the CHR and NIH initiated investigations. Overnight, the trial transformed into a focus of anxiety and hostility from the CHR. While the majority of individuals remained supportive, a small group of obstetricians completely lost confidence in the enterprise. They viewed the FTP as a significant maternal threat created by desperate attempts to fix already doomed fetuses. Just after the NIH announced their investigation, Harrison was asked to appear at an urgent Obstetrics and Gynecology department meeting to discuss the future of the FTP. Knowing well that the enterprise of fetal therapy could end that day, Harrison stood alone at that meeting and defended the fledgling field of maternal-fetal surgery for 7-hours (63).

The events of that day would forever leave a mark on fetal therapy at UCSF and arguably influence the course of the international enterprise. The UCSF FTP was dissolved on the spot and relationships with collaborators, as well as the CHR, were shredded. Eventually the trial re-opened but the impact of events lasted. While difficult, the experience proved to be a necessary step to strengthen fetal therapy at UCSF. Immediately after leaving the meeting, Harrison started restructuring fetal treatment at UCSF. The sudden collapse of the FTP almost immediately led to the founding of the UCSF Fetal Treatment Center that exists today (63).

The CDH trial was completed in 1996 after a total of 4 repairs. Results were disappointing. They had previously shown that fetuses with the most severe defects (i.e., herniation of the liver into the chest) could not be fixed and now this trial showed that milder cases did not need in utero repair because, they did just as well with repair after birth (26). Harrison immediately called a moratorium on open fetal repair of CDH. The trial's greatest value was in forcing change and growth of the enterprise of fetal surgery. The lessons learned while navigating the challenges created by the trial would inform the gold-standard research practices that are a cornerstone of the enterprise today. Harrison's early concerns proved correct. The field of fetal therapy was fragile. It could be derailed at any moment and had proven to be quickly demonized by previous supporters.
Despite the ongoing turmoil surrounding the $\mathrm{CDH}$ trial, landmark events in maternal-fetal surgery continued. Innovation in fetoscopy and the availability of smaller, less invasive equipment contributed to the revival of fetoscopic and minimally invasive interventions in the late 1980s (76). The further development of fetoscopic capabilities expedited advancements in both animal models and clinical practice. In the 1990s, Rodeck at King's College, Nicolaides at Harris Birthright Centre, and Deprest in Leuven, championed the European resurgence of fetoscopy. Early adoption at major European training centers expedited the dissemination of fetoscopic interventions throughout Western Europe (44).

Early advances in fetoscopy resulted in the rapid adoption of fetoscopic approach for treatment of twin-twin transfusion syndrome (TTTS). De Lia reported the first use of fetoscopic directed laser coagulation for TTTS in 1990 (23). The availability of a minimally invasive option inherently well suited to laser-based interventions, lead to the rapid uptake of fetoscopic interventions for TTTS. In just a few years, the adoption of laser coagulation under fetoscopic guidance was steadily increasing in the US and across Europe $(77,78)$.

The application of fetoscopy was being explored across the field of fetal intervention. Quintero, and pediatric urology group at Wayne State, developed percutaneous fetal cystoscopy, reporting the diagnostic use (31) and later its therapeutic use (47). The simultaneous innovation in fetoscopy at several major centers all over the world lead to the rapid advancement of fetoscopic techniques. The advances in fetoscopy during the early 1990s were the steppingstones to establishing the field of modern fetoscopic surgery.

Spearheaded by Harrison's group at UCSF, in 1992 therapeutic fetoscopy was developed in a fetal lamb model. The technique was dubbed "Fetendo". The unified international enthusiasm for fetoscopic interventions reflected the community's high hopes that fetoscopy would finally be the answer to decreasing the risk of premature preterm rupture of membranes (PPROM) and preterm labor, allow for earlier fetal intervention and decrease fetal risk overall (25). Work in animal models led to the development of amnioinfusion (79), established fetal safety with intra-uterine pressures of $20 \mathrm{mmHg}$ or less (33), and demonstrated preservation of uteroplacental oxygen delivery with fetoscopy (80). The stage was set for modern fetoscopic surgery.

As the groundwork for modern fetoscopic surgery was 
being established, another major shift in the philosophy of fetal interventions was occurring. In the early 1990s, fetal interventions moved away from purely anatomic repairs. Instead, innovative new interventions aimed to strategically manipulate physiology to induce a desired outcome. In the early 1990s, Harrison's group encountered a rare fetal condition in which fetal tracheal obstruction, usually laryngeal atresia, led to overgrowth of the fetal lungs, or "superlungs". Dubbed CHAOS (Congenital High Airway Obstruction Syndrome) by Martinez-Ferro, a research fellow, this discovery led the team down a new path for growing the fetal lung in CDH (81). In 1993, Wilson's group from Boston Children's Hospital reported that fetal tracheal occlusion (TO) results in tremendous lung growth (82) and parallel growth of the vasculature (83). These landmark findings helped usher in a new way of approaching fetal intervention and contributed to the rise of a novel approach to fetal $\mathrm{CDH}$.

From 1992 to 1996, after halting open repair of CDH, Harrison's group focused on the experimental animal work that laid the groundwork for fetoscopic TO for CDH. The "plug the lung until it grows" (PLUG) approach to reversibly occlude the fetal trachea showed promising results in a fetal lamb model (28). Further development and subsequent refinement of the PLUG approach (84) enabled the development of the Fetendo-plug, an internal foam plug (37), and Fetendo-clip, an external tracheal clip (40). Both techniques were initially developed with an open approach but quickly adapted to fetoscopic approaches. The group's early work culminated in 1997 with success of the first in-human fetal Fetendo-clip procedure (40). Simultaneously, the group developed the Ex Utero Intrapartum Treatment (EXIT) procedure for neonatal upper airway occlusion. The timely clinical readiness of the EXIT procedure ensured the safe reversal of iatrogenic TO in neonates that had undergone prior fetal intervention for $\mathrm{CDH}$ (30). Since the time it was first described, the EXIT procedure has been widely adapted to accommodate a range of indications and interventions that benefit from use of continued placental support for fetal oxygenation (51,85-87).

The 1990s would see one more evolutionary milestone for the fetal therapy enterprise that would lead to the first fetal intervention for a non-lethal lesion. The rising interest in fetal intervention for MMC began in the early 1990s. The shift in focus to the repair of a non-lethal lesion is further evidence of the evolving viewpoint of the community. The general acceptance, and later adoption, of fetal intervention for MMC indicates that, for the first time ever, the field of maternal-fetal surgery was ready to accept the risks of fetal surgery in an effort to reduce postnatal morbidity (3). The openness to fetal intervention to improve morbidity alone despite perioperative risks, is likely also a reflection of advancing surgical techniques and, as a result, reduced perioperative risk.

Several animal models were developed over the course of the 1980s and early 1990s. Since the earliest data from Michejda's work in primates at the NIH, animal work has produced promising results. The fetal lamb model of repair was carried out at UCSF by Meuli, Meuli-Simmen and Adzick. Overall, reported outcomes after repair have indicated improved neurological function, better distal neurologic function, and reversal of the associated ArnoldChiari II malformation (19,32,88-90).

After demonstrating feasibility in an animal model (27), Bruner and the group at Vanderbilt in 1996 reported the first 2 fetal repairs of MMC, both endoscopic. The group quickly abandoned the endoscopic technique due to a high rate of fetal mortality (39), and went on to complete the first open repair $(39,41,91,92)$. Almost simultaneously, Adzick reported what they believed to be the first open repair for fetal MMC (93). The mortality seen with the initial endoscopic experience in fetal MMC caused the US enterprise to discard endoscopic techniques for MMC for almost 20 years. While development of endoscopic techniques would be re-adopted in Europe (94-97), the US community was more tentative. Today, Farmer's group at UC Davis continues to spearhead evaluation of endoscopic techniques with unprecedented animal model work (98-104). The conversation comparing open and endoscopic approaches is ongoing (105-107).

\section{A standard is established-the rise of randomized, controlled trials and ethics of a rapidly expanding enterprise}

The early challenges around the first NIH trial for CDH raised a wide array of troublesome problems. However, addressing those issues are directly responsible for the more resilient version of the enterprise that exists today. Three momentous trends, each a pillar of modern fetal therapy, were set in motion. (I) The innovation and adoption of fetoscopic techniques, (II) the rise of novel interventions developed based on physiologic rationale, as opposed to anatomy, and (III) the community's recognition of the need for randomized, controlled trials (RCT) and rigorous scientific evaluation of fetal interventions to inform clinical 
practice (63).

RCTs are widely recognized as the key to advancing medical interventions and therapies. However, RCTs are challenging-randomization can be ethically difficult, studies are often incredibly expensive and difficult to fund, protocols can be problematic to organize, and trials are often difficult to execute well. One of the earliest calls for RCTs was Mannings' report on the early findings of the national outcomes registries in 1986 (68). The NIH CDH trial highlighted the need for more rigorous practices. The lessons learned from navigating the $\mathrm{CDH}$ trial heavily contributed to the success of the first few RCTs.

In Europe, support from the European Commission transformed European maternal-fetal surgery into a powerhouse of innovation. The establishment of the Eurofetus Consortium (EFC) in 1998 marked the beginning of a new era. Funded by the European Commission, the EFC made the resources needed for rapid clinical innovation and sound scientific evaluation readily available across Europe. The European Commission supported the fetal enterprise in three essential ways: (I) it established a consortium of major fetal treatment centers, (II) it solidified a collaborative relationship with Karl Storz to stimulate innovation in fetoscopic technology, and (III) it increased the amount and long-term availability of funding dedicated to the field $(43,44)$. In doing so, the EFC effectively dropped the barriers to executing RCTs, made specialized fetoscopic instruments more accessible, and removed the roadblocks to international collaboration across Europe.

The first 2 RCTs of modern maternal-fetal surgery both began in 1999. In Europe, with support from the newly minted EFC, a multi-center RCT comparing fetoscopic laser ablation and amnioreduction for the treatment of severe TTTS started in January. Two years later, after 142 women were randomized, the study was closed early after the interim analysis showed clear superiority of laser ablation. The study was the first step to establishing endoscopic laser coagulation as the preferred intervention for severe TTTS before 26 weeks (45). Follow-up studies reported superior neurological outcomes at $2-4$ years of age which further supported the use of laser ablation $(108,109)$. The impact the EFC would have in Europe was evident from the start. In just a few years, the EFC supported the work that would make fetoscopic laser ablation for severe TTTS the first intervention with clearly established benefit and acceptable risks.

In the US, Harrison's group had continued to develop fetoscopic techniques for reversible fetal TO. After developing the Fetendo-plug and Fetendo-clip, they next adapted a detachable balloon used in interventional radiology for occlusion of the fetal trachea. The balloon could be placed by fetoscopic bronchoscopy (49). These early techniques were applied clinically in 2 successful inhuman cases, both with encouraging results suggesting improved survival (46). In April 1999, patient recruitment began for the first US RCT evaluating the Fetendo-balloon for treatment of severe $\mathrm{CDH}$, excluding patients with liver herniation. After 24 patients were randomized, the trial ended early in July 2001 after interim analysis showed equivocal results. Additionally, all of the mothers in the intervention cohort developed PPROM and preterm labor causing significant maternal morbidity as well as lower average infant birthweight and gestational age at birth (110). Despite far greater prematurity in the intervention group, survival was equivalent to the control group born near term. This suggested that TO had some benefit which helped motivate continued work developing balloon TO in Europe.

As the field's inaugural RCTs were taking place, planning for the Management of Myelomeningocele (MOM) trial was underway. In the late 1990s, the groups at Vanderbilt and CHOP continued growing their experience with open repair of fetal MMC with promising neurological outcomes $(42,111)$. By the end of the year, the calls for more rigorous evaluation of intervention for fetal MMC increased (112). In Sep 2000, at the $19^{\text {th }}$ annual meeting of the IFMSS, early trial collaborators started planning for an RCT (3). Several key decisions were made early: (I) involvement would be limited to only 3 centers (CHOP, Vanderbilt, UCSF), (II) no other centers in North America would offer repair during the trial, (III) surgical techniques would be standardized, and (IV) initial patient assessment would be done by an independent center (George Washington University) (3). Two years of careful planning with close collaboration between all involved centers went into creating the MOMs trial, a multi-center RCT evaluating open fetal repair for MMC. Patients would be screened by the team at George Washington University and, if selected, referred randomly to one of the three MOMs surgical centers. The trial would be expensive but created a way to rigorously evaluate an intervention for an otherwise prohibitively rare pathology. After obtaining funding from the National Institute of Child Health and Human Development (NICHD), the trial opened in 2002, though it would be a year before the first patient was enrolled (3). The international enterprise of maternal-fetal surgery would be changed forever. 
From 2002-2010, a total of 299 mothers were referred to a MOMs surgical site, of which 183 were randomized. On December $7^{\text {th }} 2010$, the data safety and monitoring board recommended the trial terminate due to the clear efficacy of prenatal repair (52). Fetal repair resulted in decreased need for ventriculoperitoneal shunt placement for hydrocephalus, reversal of hindbrain herniation, and improved ability to walk at 30 months (52). However, the rate of maternal complications were not insignificant and the investigators emphasized the maternal morbidity associated with open repair (52).

The success of the MOMs trial was a landmark accomplishment. The creative trial design proved that a multi-center RCT was possible for even rare fetal pathologies. The trial highlighted collaboration among investigators and cooperation between centers as cardinal to the thorough evaluation of fetal therapies, a concept first made evident by the early successes of the EFC. The MOMs trial was a testament to what the cooperative efforts of the fetal therapy community were capable of accomplishing. MOMs set a new standard for the international field of maternal-fetal surgery. High-quality evidence demonstrating the efficacy and safety of fetal therapies was becoming the community's expectation and solidified the need for more rigorous evaluation of interventions (113).

As the MOMs trial was ongoing, investigation of balloon TO for CDH continued in Europe and would eventually become a landmark international multi-center RCT. From the late 1990s into the 2000s, the percutaneous fetoscopic Endoluminal Tracheal Occlusion (FETO) procedure was developed by a European consortium, the FETO task force, established to facilitate the investigation and development of balloon tracheal occlusion for CDH (44). The FETO task force made advances in the timing and techniques for the FETO procedure, that included refining percutaneous uterine access for balloon placement (50). Discoveries made by Flageole and O'Toole improved the understanding of the pathophysiology of tracheal occlusion $(114,115)$ and lead to the development of a second procedure to facilitate timed in-utero removal of the balloon $(50,116)$. Not only did timed in-utero balloon removal improve outcomes, but, for the first time ever, also made vaginal delivery possible after fetal intervention. A landmark in improving maternal morbidity by eliminating risks related to $\mathrm{C}$-section delivery.

In 2001, with support from the EFC, a multi-center prospective observational trial (FETO trial) evaluating the FETO procedure for severe $\mathrm{CDH}$ was launched. From 2001 to 2008, 210 FETO procedures were performed and resulted in significant survival benefit in $\mathrm{CDH}(117,118)$. Their initial experiences led to further refinement of the balloon, to ensure complete tracheal occlusion, and techniques for balloon removal $(50,118)$. PPROM continued to be a challenge and was found to increase risk of early delivery and infant mortality 5 -fold (118).

With the ongoing success of the MOMs trial, the FETO consortium acknowledged that an RCT was required to substantiate the survival benefit shown in the FETO trial (56). Following the blueprint established by the MOMs trial, two multi-center RCTs, named the TOTAL trials, were designed to evaluate the FETO procedure performed either early or late in pregnancy in cohorts of $\mathrm{CDH}$ with both severe and moderate pulmonary hypoplasia. The trial design employed standardized surgical techniques, postnatal management and guidelines for patient selection based on rigorous criteria to ensure a homogenous study population (56). The first TOTAL trial for moderate pulmonary hypoplasia launched in 2009 and a second trial for severe pulmonary hypoplasia was launched in quick succession. The TOTAL trials rapidly gained attention from the community and in just a few years expanded to become multi-center, multi-national efforts. By 2014, the trials were reported to be in the process of extending to the US, Canada, Australia and Japan (119). The moderate TOTAL trial was underway in multiple centers in the US by 2017 and had strong support from the international community (120). The moderate TOTAL trial ended recruitment in May 2019 and the results remain highly anticipated. A few months after the moderate arm closed, the same centers began recruiting for the TOTAL trial for severe pulmonary hypoplasia (121).

The MOMs trial laid the foundation for the TOTAL trial and many RCTs to come. But the wild success of MOMs, and the clear benefit with fetal repair that was demonstrated, also led to the expansion of the enterprise at an unprecedented rate. After the publication of the MOMs results, new fetal treatment centers were established across the county. Open repair of fetal MMC quickly became the most common fetal surgery performed in the US (122). According to a survey conducted in $2014,76 \%$ of fetal centers in the US had been opened within the last 10 years. Additionally, the survey demonstrated significant variability in practice patterns and resource availability between centers (123).

The accelerated growth of the enterprise as a result of the MOMs trial created major challenges around how to maintain the highest quality of clinical care and ensure 
that new innovation and research would be conducted responsibly and ethically. The years after the MOMs trial have been characterized by the actions the community of fetal therapy have taken in an effort to protect the field as a whole. Just as Harrison emphasized when the enterprise was first founded, maintaining credibility with the public is paramount and will always be a delicate matter $(60,63)$. The IFMSS member's commitment to the stewardship of the enterprise were as crucial as ever.

The North American Fetal Therapy Network (NAFTNet) is prime evidence of how the leaders of the fetal therapy community responded to the evolving challenges of the growing enterprise. In January 2004, at a Society of Maternal Fetal Medicine meeting, clinical investigators from the MOMs centers, with the success of the MOMs trial fresh on their minds, came to mutually agree that a new age of cooperation and collaborative research was essential to the advancement of the field of fetal therapy (55). Based on that initial conversation, those 4 centers (UCSF, CHOP, Vanderbilt, University of North Carolina - Chapel Hill) formed the 'Fetal Therapy Working Group' research collaborative (55). In August of that year, in recognition of the emerging field, the NIH organized a workshop on fetal therapy with the intention of developing a national plan for patient diagnosis and dissemination of innovation to improve patient outcomes. At the conclusion of the workshop, the NIH formally recommended the formation of a cooperative group of clinicians and investigators that would define the national agenda for both research and clinical practice in the field of fetal therapy (55). The 'Fetal Therapy Working Group' rose to the occasion.

Just a few months later, the concept and organizational structure of NAFTNet had been established and by the following year the first 12 centers accepted invitations to join as the founding members. Conscientiously structured to be multidisciplinary, NAFTNet was the first official cooperative clinical research network in the US with standardized research practices designed to facilitate the practice of evidence based fetal medicine. NAFTNet was established to meet 4 primary goals: (I) study the natural history of fetal disease, (II) develop prenatal interventions to improve outcomes, (III) provide educational resources for patients and healthcare providers, and (IV) train future leaders in both clinical practice and research in fetal intervention. The success of NAFTNet was immediately apparent. In just a few years, NAFTNet was supporting numerous research efforts and had sponsored an International Consensus Conference on the Management of Quintero Stage I TTTS. By 2010, the collaborative was involved in 8 active research studies. Today, NAFTNet includes 36 multi-disciplinary advanced fetal treatment centers in the US and Canada and currently supports over 6 active research studies and 4 clinical trials, including the TOTAL trial and the NIH funded Renal Anhydramnios (RAFT) Trial (124). As the field of maternal-fetal surgery has evolved ever more rapidly, NAFTNet has played a crucial role in guiding the national conversation and setting a standard of excellence (125).

Following the example set by the first consensus statement from the IFMSS, publications in recent years have created an ongoing discussion in the literature on the ethical and responsible practice of maternal-fetal surgery. In response to the surge in new fetal treatment centers over the last 10 years, recommendations for standard guidelines and clinical requirements for all fetal treatment centers started to take shape. The same year the MOMs results were published, the NICHD established the Maternal-Fetal Medicine (MFM) Task Force (3) and a joint statement on new fetal treatment centers was published by the ethics committees from the American College of Obstetricians and Gynecologists and the American Academy of Pediatrics (126). In 2014, the MFM task force established operational guidelines for fetal treatment centers that included strongly worded recommendations that all centers offering fetal MMC repair follow the MOMs protocols to ensure centers produce minimal comparable outcomes (127).

The community put forward universal requirements for all centers offering maternal-fetal surgery and worked to establish minimum standards for the multi-disciplinary team necessary for effective delivery of fetal therapy (128). There has been a strong consensus in the literature that transparency should be required of all fetal treatment centers in regards to their clinical capabilities, available resources, case volume and prior experience $(60,129)$. Minimum practice standards and reporting requirements would allow for fetal treatment centers to be ranked on a clinical grading scale, similar to the level of verification assigned for NICUs and trauma centers.

In parallel to clinical standards of care, guidelines for responsible innovation and research in maternal-fetal surgery have also been put forward by the community. The paradox inherent to maternal-fetal surgery is that the surgeon is often the innovator, researcher and clinicalcare provider all at once, but must maintain a clear division between the motivations of those roles (60). The ethical 
pursuit of innovation demands the complex balance between the risk of morbidity for the pregnant women against the potential benefit for her child $(130,131)$. Recent guidelines have attempted to clarify the previously blurry progression from innovation to clinical practice (60). Three defined stages have been outlined: innovation (pre-research), research and transition to clinical practice (131).

Like the thoughtful recommendations put forward by the IFMSS in 1982, current guidelines have established a clear continuum between innovation, research and clinical practice in an effort to ensure the continued success of the enterprise (131). The IFMSS emphasis on every member's commitment to be a steward of the field is more vital today than ever.

\section{Acknowledgments}

The authors would like to acknowledge all of the pediatric surgeons, neonatologists, obstetricians, radiologists, anesthesiologists, pediatricians and all the providers from across all walks of medicine who have helped make maternal-fetal surgery what it is today. Special recognition and thanks must be given to the dedicated, passionate and hardworking research fellows around the world who have helped make fetal surgery the progressive and rapidly advancing field it has been for the last 40 years. However, most of all, the authors would like to thank all of the patients and families who have also been on this remarkable journey.

Funding: None.

\section{Footnote}

Provenance and Peer Review: This article was commissioned by the Guest Editors (Eric B. Jelin and George B. Mychaliska) for the series "Fetal Surgery" published in Translational Pediatrics. The article has undergone external peer review.

Conflicts of Interest: Both authors have completed the ICMJE uniform disclosure form (available at http://dx.doi. org/10.21037/tp-20-114). The series "Fetal Surgery" was commissioned by the editorial office without any funding or sponsorship. The authors have no other conflicts of interest to declare.

Ethical Statement: The authors are accountable for all aspects of the work in ensuring that questions related to the accuracy or integrity of any part of the work are appropriately investigated and resolved.

Open Access Statement: This is an Open Access article distributed in accordance with the Creative Commons Attribution-NonCommercial-NoDerivs 4.0 International License (CC BY-NC-ND 4.0), which permits the noncommercial replication and distribution of the article with the strict proviso that no changes or edits are made and the original work is properly cited (including links to both the formal publication through the relevant DOI and the license). See: https://creativecommons.org/licenses/by-nc-nd/4.0/.

\section{References}

1. Liley AW. Intrauterine Transfusion of Foetus in Haemolytic Disease. Br Med J 1963;2:1107-9.

2. Asensio SH, Figueroa-Longo JG, Pelegrina IA. Intrauterine exchange transfusion. Am J Obstet Gynecol 1966;95:1129-33.

3. Kitagawa H, Pringle KC. Fetal surgery: a critical review. Pediatr Surg Int 2017;33:421-33.

4. Hobbins JC, Mahoney MJ. In utero diagnosis of hemoglobinopathies. Technic for obtaining fetal blood. N Engl J Med 1974;290:1065-7.

5. Rodeck CH. Value of fetoscopy in prenatal diagnosis. J R Soc Med 1980;73:29-33.

6. Harrison MR, Bressack MA, Churg AM, et al. Correction of congenital diaphragmatic hernia in utero. II. Simulated correction permits fetal lung growth with survival at birth. Surgery 1980;88:260-8.

7. Harrison MR, Ross NA, de Lorimier AA. Correction of congenital diaphragmatic hernia in utero. III.

Development of a successful surgical technique using abdominoplasty to avoid compromise of umbilical blood flow. J Pediatr Surg 1981;16:934-42.

8. Harrison MR, Jester JA, Ross NA. Correction of congenital diaphragmatic hernia in utero. I. The model: intrathoracic balloon produces fatal pulmonary hypoplasia. Surgery 1980;88:174-82.

9. Nakayama DK, Harrison MR, Seron-Ferre M, et al. Fetal surgery in the primate II. Uterine electromyographic response to operative procedures and pharmacologic agents. J Pediatr Surg 1984;19:333-9.

10. Adzick NS, Harrison MR, Glick PL, et al. Fetal surgery in the primate. III. Maternal outcome after fetal surgery. J Pediatr Surg 1986;21:477-80.

11. Harrison MR, Anderson J, Rosen MA, et al. Fetal surgery 
in the primate I. Anesthetic, surgical, and tocolytic management to maximize fetal-neonatal survival. J Pediatr Surg 1982;17:115-22.

12. Hodgen GD. Antenatal diagnosis and treatment of fetal skeletal malformations. With emphasis on in utero surgery for neural tube defects and limb bud regeneration. JAMA 1981;246:1079-83.

13. Michejda M, Hodgen GD. In utero diagnosis and treatment of non-human primate fetal skeletal anomalies. I. Hydrocephalus. JAMA 1981;246:1093-7.

14. Harrison MR, Ross N, Noall R, et al. Correction of congenital hydronephrosis in utero. I. The model: fetal urethral obstruction produces hydronephrosis and pulmonary hypoplasia in fetal lambs. J Pediatr Surg 1983;18:247-56.

15. Harrison MR, Golbus MS, Filly RA, et al. Fetal surgery for congenital hydronephrosis. N Engl J Med 1982;306:591-3.

16. Clewell WH, Johnson ML, Meier PR, et al. A surgical approach to the treatment of fetal hydrocephalus. N Engl J Med 1982;306:1320-5.

17. Bang J, Bock JE, Trolle D. Ultrasound-guided fetal intravenous transfusion for severe rhesus haemolytic disease. Br Med J (Clin Res Ed) 1982;284:373-4.

18. Harrison MR, Filly RA, Golbus MS, et al. Fetal treatment 1982. N Engl J Med 1982;307:1651-2.

19. Michejda $M$. Intrauterine treatment of spina bifida: primate model. Z Kinderchir 1984;39:259-61.

20. Harrison MR, Adzick NS, Jennings RW, et al. Antenatal intervention for congenital cystic adenomatoid malformation. Lancet 1990;336:965-7.

21. Adzick NS, Harrison MR, Flake AW, et al. Fetal surgery for cystic adenomatoid malformation of the lung. J Pediatr Surg 1993;28:806-12.

22. Harrison MR, Adzick NS, Longaker MT, et al. Successful repair in utero of a fetal diaphragmatic hernia after removal of herniated viscera from the left thorax. N Engl J Med 1990;322:1582-4.

23. De Lia JE, Cruikshank DP, Keye WR Jr. Fetoscopic neodymium:YAG laser occlusion of placental vessels in severe twin-twin transfusion syndrome. Obstet Gynecol 1990;75:1046-53.

24. Maxwell D, Allan L, Tynan MJ. Balloon dilatation of the aortic valve in the fetus: a report of two cases. Br Heart J 1991;65:256-8.

25. Estes JM, MacGillivray TE, Hedrick MH, et al. Fetoscopic surgery for the treatment of congenital anomalies. J Pediatr Surg 1992;27:950-4.

26. Harrison MR, Adzick NS, Bullard KM, et al. Correction of congenital diaphragmatic hernia in utero VII: a prospective trial. J Pediatr Surg 1997;32:1637-42.

27. Copeland ML, Bruner JP, Richards WO, et al. A model for in utero endoscopic treatment of myelomeningocele. Neurosurgery 1993;33:542-4; discussion 5.

28. Hedrick MH, Estes JM, Sullivan KM, et al. Plug the lung until it grows (PLUG): a new method to treat congenital diaphragmatic hernia in utero. J Pediatr Surg 1994;29:612-7.

29. Quintero RA, Reich H, Puder KS, et al. Brief report: umbilical-cord ligation of an acardiac twin by fetoscopy at 19 weeks of gestation. N Engl J Med 1994;330:469-71.

30. Harrison MR, Adzick NS, Flake AW, et al. Correction of congenital diaphragmatic hernia in utero VIII: Response of the hypoplastic lung to tracheal occlusion. J Pediatr Surg 1996;31:1339-48.

31. Quintero RA, Hume R, Smith C, Johnson MP, Cotton DB, Romero R, et al. Percutaneous fetal cystoscopy and endoscopic fulguration of posterior urethral valves. Am J Obstet Gynecol 1995;172:206-9.

32. Meuli M, Meuli-Simmen C, Yingling CD, et al. Creation of myelomeningocele in utero: a model of functional damage from spinal cord exposure in fetal sheep. J Pediatr Surg 1995;30:1028-2.

33. Skarsgard ED, Bealer JF, Meuli M, et al. Fetal endoscopic ('Fetendo') surgery: the relationship between insufflating pressure and the fetoplacental circulation. J Pediatr Surg 1995;30:1165-8.

34. Graf JL, Albanese CT, Jennings RW, et al. Successful fetal sacrococcygeal teratoma resection in a hydropic fetus. J Pediatr Surg 2000;35:1489-91.

35. Adzick NS, Crombleholme TM, Morgan MA, et al. A rapidly growing fetal teratoma. Lancet 1997;349:538-8.

36. Hecher K, Hackeloer BJ. Intrauterine endoscopic laser surgery for fetal sacrococcygeal teratoma. Lancet 1996;347:470-8.

37. Skarsgard ED, Meuli M, VanderWall KJ, et al. Fetal endoscopic tracheal occlusion ('Fetendo-PLUG') for congenital diaphragmatic hernia. J Pediatr Surg 1996;31:1335-8.

38. VanderWall KJ, Bruch SW, Meuli M, et al. Fetal endoscopic ('Fetendo') tracheal clip. J Pediatr Surg 1996;31:1101-3.

39. Bruner JP, Tulipan NE, Richards WO. Endoscopic coverage of fetal open myelomeningocele in utero. Am J Obstet Gynecol 1997;176:256-7.

40. VanderWall KJ, Skarsgard ED, Filly RA, et al. Fetendoclip: a fetal endoscopic tracheal clip procedure in a human 
fetus. J Pediatr Surg 1997;32:970-2.

41. Bruner JP, Tulipan NB, Richards WO, et al. In utero repair of myelomeningocele: a comparison of endoscopy and hysterotomy. Fetal Diagn Ther 2000;15:83-8.

42. Bruner JP, Tulipan N, Paschall RL, et al. Fetal surgery for myelomeningocele and the incidence of shunt-dependent hydrocephalus. JAMA 1999;282:1819-25.

43. Deprest JA, Gratacos E. Obstetrical endoscopy. Curr Opin Obstet Gynecol 1999;11:195-203.

44. Deprest JA, Flake AW, Gratacos E, et al. The making of fetal surgery. Prenat Diagn 2010;30:653-67.

45. Senat MV, Deprest J, Boulvain M, et al. Endoscopic laser surgery versus serial amnioreduction for severe twin-to-twin transfusion syndrome. N Engl J Med 2004;351:136-44.

46. Harrison MR, Sydorak RM, Farrell JA, et al. Fetoscopic temporary tracheal occlusion for congenital diaphragmatic hernia: prelude to a randomized, controlled trial. J Pediatr Surg 2003;38:1012-20.

47. Quintero RA, Shukla AR, Homsy YL, et al. Successful in utero endoscopic ablation of posterior urethral valves: a new dimension in fetal urology. Urology 2000;5 5:774-8.

48. Sydorak RM, Kelly T, Feldstein VA, et al. Prenatal resection of a fetal pericardial teratoma. Fetal Diagn Ther 2002;17:281-5.

49. Harrison MR, Albanese CT, Hawgood SB, et al. Fetoscopic temporary tracheal occlusion by means of detachable balloon for congenital diaphragmatic hernia. Am J Obstet Gynecol 2001;185:730-3.

50. Deprest J, Gratacos E, Nicolaides KH, et al. Fetoscopic tracheal occlusion (FETO) for severe congenital diaphragmatic hernia: evolution of a technique and preliminary results. Ultrasound Obstet Gynecol 2004;24:121-6.

51. Hirose S, Sydorak RM, Tsao K, et al. Spectrum of intrapartum management strategies for giant fetal cervical teratoma. J Pediatr Surg 2003;38:446-50.

52. Adzick NS, Thom EA, Spong CY, et al. A randomized trial of prenatal versus postnatal repair of myelomeningocele. N Engl J Med 2011;364:993-1004.

53. Crombleholme TM, Shera D, Lee H, et al. A prospective, randomized, multicenter trial of amnioreduction vs selective fetoscopic laser photocoagulation for the treatment of severe twin-twin transfusion syndrome. Am J Obstet Gynecol 2007;197:396.e1-9.

54. Cortes RA, Wagner AJ, Lee H, et al. Pre-emptive placement of a presealant for amniotic access. Am J Obstet Gynecol 2005;193:1197-203.
55. Johnson MP. The North American Fetal Therapy Network (NAFTNet): a new approach to collaborative research in fetal diagnosis and therapy. Semin Fetal Neonatal Med 2010;15:52-7.

56. Dekoninck P, Gratacos E, Van Mieghem T, et al. Results of fetal endoscopic tracheal occlusion for congenital diaphragmatic hernia and the set up of the randomized controlled TOTAL trial. Early Hum Dev 2011;87:619-24.

57. Pedreira DA, Zanon N, Nishikuni K, et al. Endoscopic surgery for the antenatal treatment of myelomeningocele: the CECAM trial. Am J Obstet Gynecol 2016;214:111.e1-11.

58. Luks FI, Johnson A, Polzin WJ, et al. Innovation in maternal-fetal therapy: a position statement from the North American Fetal Therapy Network. Obstet Gynecol 2015;125:649-52.

59. MacKenzie TC. Future AAVenues for In Utero Gene Therapy. Cell Stem Cell 2018;23:320-1.

60. Antiel RM, Flake AW. Responsible surgical innovation and research in maternal-fetal surgery. Semin Fetal Neonatal Med 2017;22:423-7.

61. Adamsons K Jr. Fetal surgery. N Engl J Med 1966;275:204-6.

62. Harrison MR. What if?... Why not? J Pediatr Surg 2010;45:1-10.

63. Harrison MR. The University of California at San Francisco Fetal Treatment Center: a personal perspective. Fetal Diagn Ther 2004;19:513-24.

64. Harrison MR, Bjordal RI, Langmark F, et al. Congenital diaphragmatic hernia: the hidden mortality. J Pediatr Surg 1978;13:227-30.

65. Rodeck CH, Nicolaides KH, Warsof SL, et al. The management of severe rhesus isoimmunization by fetoscopic intravascular transfusions. Am J Obstet Gynecol 1984;150:769-74.

66. Kabagambe SK, Lee CJ, Goodman LF, et al. Lessons from the Barn to the Operating Suite: A Comprehensive Review of Animal Models for Fetal Surgery. Annu Rev Anim Biosci 2018;6:99-119.

67. Harrison MR, Nakayama DK, Noall R, de Lorimier AA. Correction of congenital hydronephrosis in utero II. Decompression reverses the effects of obstruction on the fetal lung and urinary tract. J Pediatr Surg 1982;17:965-74.

68. Manning FA, Harrison MR, Rodeck C. Catheter shunts for fetal hydronephrosis and hydrocephalus. Report of the International Fetal Surgery Registry. N Engl J Med 1986;315:336-40.

69. Nakayama DK, Harrison MR, Chinn DH, et al. Prenatal 
diagnosis and natural history of the fetus with a congenital diaphragmatic hernia: initial clinical experience. J Pediatr Surg 1985;20:118-24.

70. Pringle KC, Turner JW, Schofield JC, et al. Creation and repair of diaphragmatic hernia in the fetal lamb: lung development and morphology. J Pediatr Surg 1984;19:131-40.

71. Adzick NS, Outwater KM, Harrison MR, et al. Correction of congenital diaphragmatic hernia in utero. IV. An early gestational fetal lamb model for pulmonary vascular morphometric analysis. J Pediatr Surg 1985;20:673-80.

72. Harrison MR, Langer JC, Adzick NS, et al. Correction of congenital diaphragmatic hernia in utero, V. Initial clinical experience. J Pediatr Surg 1990;25:47-55.

73. Harrison MR, Adzick NS, Flake AW, et al. Correction of congenital diaphragmatic hernia in utero: VI. Hard-earned lessons. J Pediatr Surg 1993;28:1411-7.

74. DiFederico EM, Burlingame JM, Kilpatrick SJ, et al. Pulmonary edema in obstetric patients is rapidly resolved except in the presence of infection or of nitroglycerin tocolysis after open fetal surgery. Am J Obstet Gynecol 1998;179:925-33.

75. DiFederico EM, Harrison M, Matthay MA. Pulmonary edema in a woman following fetal surgery. Chest 1996;109:1114-7.

76. Graves CE, Harrison MR, Padilla BE. Minimally Invasive Fetal Surgery. Clin Perinatol 2017;44:729-51.

77. De Lia JE, Kuhlmann RS, Harstad TW, et al. Fetoscopic laser ablation of placental vessels in severe previable twin-twin transfusion syndrome. Am J Obstet Gynecol 1995;172:1202-8.

78. Ville Y, Hyett J, Hecher K, et al. Preliminary experience with endoscopic laser surgery for severe twin-twin transfusion syndrome. N Engl J Med 1995;332:224-7.

79. Luks FI, Deprest J, Marcus M, et al. Carbon dioxide pneumoamnios causes acidosis in fetal lamb. Fetal Diagn Ther 1994;9:105-9.

80. Luks FI, Peers KH, Deprest JA, et al. The effect of open and endoscopic fetal surgery on uteroplacental oxygen delivery in the sheep. J Pediatr Surg 1996;31:310-4.

81. Hedrick MH, Ferro MM, Filly RA, et al. Congenital high airway obstruction syndrome (CHAOS): a potential for perinatal intervention. J Pediatr Surg 1994;29:271-4.

82. DiFiore JW, Fauza DO, Slavin R, et al. Experimental fetal tracheal ligation reverses the structural and physiological effects of pulmonary hypoplasia in congenital diaphragmatic hernia. J Pediatr Surg 1994;29:248-56; discussion 256-7.
83. DiFiore JW, Fauza DO, Slavin R, et al. Experimental fetal tracheal ligation and congenital diaphragmatic hernia: a pulmonary vascular morphometric analysis. J Pediatr Surg 1995;30:917-23.

84. Bealer JF, Skarsgard ED, Hedrick MH, et al. The 'PLUG' odyssey: adventures in experimental fetal tracheal occlusion. J Pediatr Surg 1995;30:361-4.

85. Hedrick HL, Flake AW, Crombleholme TM, et al. The ex utero intrapartum therapy procedure for high-risk fetal lung lesions. J Pediatr Surg 2005;40:1038-43; discussion 44.

86. Kunisaki SM, Barnewolt CE, Estroff JA, et al. Ex utero intrapartum treatment with extracorporeal membrane oxygenation for severe congenital diaphragmatic hernia. J Pediatr Surg 2007;42:98-104.

87. Lim FY, Crombleholme TM, Hedrick HL, et al. Congenital high airway obstruction syndrome: natural history and management. J Pediatr Surg 2003;38:940-5.

88. Michejda M, Patronas N, Di Chiro G, et al. Fetal hydrocephalus. II. Amelioration of fetal porencephaly by in utero therapy in nonhuman primates. JAMA 1984;251:2548-52.

89. Heffez DS, Aryanpur J, Hutchins GM, et al. The paralysis associated with myelomeningocele: clinical and experimental data implicating a preventable spinal cord injury. Neurosurgery 1990;26:987-92.

90. Meuli M, Meuli-Simmen C, Yingling CD, et al. In utero repair of experimental myelomeningocele saves neurological function at birth. J Pediatr Surg 1996;31:397-402.

91. Bruner JP, Richards WO, Tulipan NB, et al. Endoscopic coverage of fetal myelomeningocele in utero. Am J Obstet Gynecol 1999;180:153-8.

92. Tulipan N, Bruner JP. Myelomeningocele repair in utero: a report of three cases. Pediatr Neurosurg 1998;28:177-80.

93. Adzick NS, Sutton LN, Crombleholme TM, Flake AW. Successful fetal surgery for spina bifida. Lancet 1998;352:1675-6.

94. Kohl T, Hartlage MG, Kiehitz D, et al. Percutaneous fetoscopic patch coverage of experimental lumbosacral full-thickness skin lesions in sheep. Surg Endosc 2003;17:1218-23.

95. Kohl T, Hering R, Heep A, et al. Percutaneous fetoscopic patch coverage of spina bifida aperta in the human-early clinical experience and potential. Fetal Diagn Ther 2006;21:185-93.

96. Degenhardt J, Schurg R, Winarno A, et al. Percutaneous minimal-access fetoscopic surgery for spina bifida aperta. Part II: maternal management and outcome. Ultrasound 
Obstet Gynecol 2014;44:525-31.

97. Graf K, Kohl T, Neubauer BA, et al. Percutaneous minimally invasive fetoscopic surgery for spina bifida aperta. Part III: neurosurgical intervention in the first postnatal year. Ultrasound Obstet Gynecol 2016;47:158-61.

98. Yoshizawa J, Sbragia L, Paek BW, et al. Fetal surgery for repair of myelomeningocele allows normal development of anal sphincter muscles in sheep. Pediatr Surg Int 2004;20:14-8.

99. Brown EG, Keller BA, Lankford L, et al. Age Does Matter: A Pilot Comparison of Placenta-Derived Stromal Cells for in utero Repair of Myelomeningocele Using a Lamb Model. Fetal Diagn Ther 2016;39:179-85.

100. Brown EG, Keller BA, Pivetti CD, et al. Innate healing in the fetal sheep model of myelomeningocele: A standardized defect grading system. J Pediatr Surg 2015;50:1134-6.

101.Chen YJ, Chung K, Pivetti C, et al. Fetal surgical repair with placenta-derived mesenchymal stromal cell engineered patch in a rodent model of myelomeningocele. J Pediatr Surg 2017. [Epub ahead of print].

102. Kabagambe SK, Chen YJ, Vanover MA, et al. New directions in fetal surgery for myelomeningocele. Childs Nerv Syst 2017;33:1185-90.

103. Vanover M, Pivetti C, Galganski L, et al. Spinal Angulation: A Limitation of the Fetal Lamb Model of Myelomeningocele. Fetal Diagn Ther 2019;46:376-84.

104. Vanover M, Pivetti C, Lankford L, et al. High density placental mesenchymal stromal cells provide neuronal preservation and improve motor function following in utero treatment of ovine myelomeningocele. J Pediatr Surg 2019;54:75-9.

105. Kabagambe SK, Jensen GW, Chen YJ, et al. Fetal Surgery for Myelomeningocele: A Systematic Review and MetaAnalysis of Outcomes in Fetoscopic versus Open Repair. Fetal Diagn Ther 2018;43:161-74.

106.Joyeux L, De Bie F, Danzer E, et al. Learning curves of open and endoscopic fetal spina bifida closure: a systematic review and meta-analysis. Ultrasound Obstet Gynecol 2020;55:730-9.

107.Danzer E, Joyeux L, Flake AW, et al. Fetal surgical intervention for myelomeningocele: lessons learned, outcomes, and future implications. Dev Med Child Neurol 2020;62:417-25.

108. Graef C, Ellenrieder B, Hecher K, et al. Longterm neurodevelopmental outcome of 167 children after intrauterine laser treatment for severe twintwin transfusion syndrome. Am J Obstet Gynecol 2006;194:303-8.
109. Lenclen R, Ciarlo G, Paupe A, et al. Neurodevelopmental outcome at 2 years in children born preterm treated by amnioreduction or fetoscopic laser surgery for twin-totwin transfusion syndrome: comparison with dichorionic twins. Am J Obstet Gynecol 2009;201:291.e1-5.

110.Harrison MR, Keller RL, Hawgood SB, et al. A randomized trial of fetal endoscopic tracheal occlusion for severe fetal congenital diaphragmatic hernia. N Engl J Med 2003;349:1916-24.

111. Sutton LN, Adzick NS, Bilaniuk LT, et al. Improvement in hindbrain herniation demonstrated by serial fetal magnetic resonance imaging following fetal surgery for myelomeningocele. JAMA 1999;282:1826-31.

112. Simpson JL. Fetal surgery for myelomeningocele: promise, progress, and problems. JAMA 1999;282:1873-4.

113. Bebbington MW. Fetal therapy: the need for well-designed collaborative research trials. Ultrasound Obstet Gynecol 2013;42:1-3.

114. Flageole H, Evrard VA, Piedboeuf B, et al. The plugunplug sequence: an important step to achieve type II pneumocyte maturation in the fetal lamb model. J Pediatr Surg 1998;33:299-303.

115. O'Toole SJ, Sharma A, Karamanoukian HL, et al. Tracheal ligation does not correct the surfactant deficiency associated with congenital diaphragmatic hernia. J Pediatr Surg 1996;31:546-50.

116. Bouchard S, Johnson MP, Flake AW, et al. The EXIT procedure: experience and outcome in 31 cases. J Pediatr Surg 2002;37:418-26.

117.Jani J, Keller RL, Benachi A, et al. Prenatal prediction of survival in isolated left-sided diaphragmatic hernia. Ultrasound Obstet Gynecol 2006;27:18-22.

118.Jani JC, Nicolaides KH, Gratacos E, et al. Severe diaphragmatic hernia treated by fetal endoscopic tracheal occlusion. Ultrasound Obstet Gynecol 2009;34:304-10.

119. Deprest J, Brady P, Nicolaides K, et al. Prenatal management of the fetus with isolated congenital diaphragmatic hernia in the era of the TOTAL trial. Semin Fetal Neonatal Med 2014;19:338-48.

120.Araujo Júnior E, Tonni G, Martins WP, et al. ProcedureRelated Complications and Survival Following Fetoscopic Endotracheal Occlusion (FETO) for Severe Congenital Diaphragmatic Hernia: Systematic Review and Meta-Analysis in the FETO Era. Eur J Pediatr Surg 2017;27:297-305.

121. The TTPC. The TOTAL Trial Website.

122. Saadai P, Farmer DL. Fetal surgery for myelomeningocele. Clin Perinatol 2012;39:279-88. 
123. Kett JC, Woodrum DE, Diekema DS. A survey of fetal care centers in the United States. J Neonatal Perinatal Med 2014;7:131-5.

124. North American Fetal Therapy Network NAFTNet: North American Fetal Therapy Network. Available online: https://www.naftnet.org/

125.Moon-Grady AJ, Baschat A, Cass D, et al. Fetal Treatment 2017: The Evolution of Fetal Therapy Centers - A Joint Opinion from the International Fetal Medicine and Surgical Society (IFMSS) and the North American Fetal Therapy Network (NAFTNet). Fetal Diagn Ther 2017;42:241-8.

126. American College of Obstetricians and Gynecologists. Committee on Ethics; American Academy of Pediatrics. Committee on Bioethics. Committee opinion no. 501:

Cite this article as: Evans LL, Harrison MR. Modern fetal surgery-a historical review of the happenings that shaped modern fetal surgery and its practices. Transl Pediatr 2021;10(5):1401-1417. doi: 10.21037/tp-20-114
Maternal-fetal intervention and fetal care centers. Obstet Gynecol 2011;118:405-10.

127. Cohen AR, Couto J, Cummings JJ, et al. Position statement on fetal myelomeningocele repair. Am J Obstet Gynecol 2014;210:107-11.

128. Watanabe M, Flake AW. Fetal surgery: progress and perspectives. Adv Pediatr 2010;57:353-72.

129. Morche J, Mathes T, Pieper D. Relationship between surgeon volume and outcomes: a systematic review of systematic reviews. Syst Rev 2016;5:204.

130. Antiel RM, Flake AW, Collura CA, et al. Weighing the Social and Ethical Considerations of Maternal-Fetal Surgery. Pediatrics 2017;140:e20170608.

131. Chervenak FA, McCullough LB. The ethics of maternalfetal surgery. Semin Fetal Neonatal Med 2018;23:64-7. 